\title{
Belphégor
}

Curreri, Luciano, Il peplum di Emilio. Storie e fonti antiche e moderne dell'immaginario salgariano (1862-2012)

Piombino, Edizioni Il Foglio, CINEMA, 2012 ( $1^{\circ}$ edizione, marzo), p. 227 ISBN 9788876063688

\section{Fabiana Dimpflmeier}

\section{(2) OpenEdition}

\section{Journals}

Edizione digitale

URL: http://journals.openedition.org/belphegor/209

DOI: $10.4000 /$ belphegor.209

ISSN: 1499-7185

Editore

LPCM

Notizia bibliografica digitale

Fabiana Dimpflmeier, « Curreri, Luciano, // peplum di Emilio. Storie e fonti antiche e moderne dell'immaginario salgariano (1862-2012) », Belphégor [En ligne], 11-1 | 2013, mis en ligne le 22 juin 2013, consulté le 22 septembre 2020. URL : http://journals.openedition.org/belphegor/209 ; DOI : https:// doi.org/10.4000/belphegor.209

Questo documento è stato generato automaticamente il 22 settembre 2020.

\section{(†) $\odot$

Belphégor est mis à disposition selon les termes de la Licence Creative Commons Attribution - Pas d'Utilisation Commerciale - Pas de Modification 4.0 International. 


\section{Curreri, Luciano, Il peplum di Emilio. Storie e fonti antiche e moderne dell'immaginario salgariano (1862-2012)}

Piombino, Edizioni Il Foglio, CINEMA, 2012 ( $1^{\circ}$ edizione, marzo), p. 227

ISBN 9788876063688

Fabiana Dimpflmeier

NOTIZIA

Luciano Curreri, Il peplum di Emilio. Storie e fonti antiche e moderne dell'immaginario salgariano (1862-2012), Piombino, Edizioni Il Foglio, CINEMA, 2012 ( $1^{\circ}$ edizione, marzo), p. 227 ISBN 9788876063688 
1 Per la collana di Claudio Zanello 'Cinema' de Il Foglio Letterario, "che comprende volumi monografici dedicati ai personaggi più complessi, multiformi, innovativi e contraddittori che hanno segnato la storia della cinematografia degli ultimi decenni..." esce questo denso, a tratti rocambolesco, vivido, sferzante volumetto di Luciano Curreri, che con passione focosa trascina nel cuore pulsante dell'immaginario salgariano e della ricezione di Salgari, a partire da Cartagine in fiamme (apparso nel 1906 a puntate su "Per terra e per mare" e nel 1908 in volume), passando per il panorama cinematografico cresciuto intorno al genere peplum dagli anni Dieci in poi, per poi tornare a riflettere su Le figlie dei faraoni del 1905.

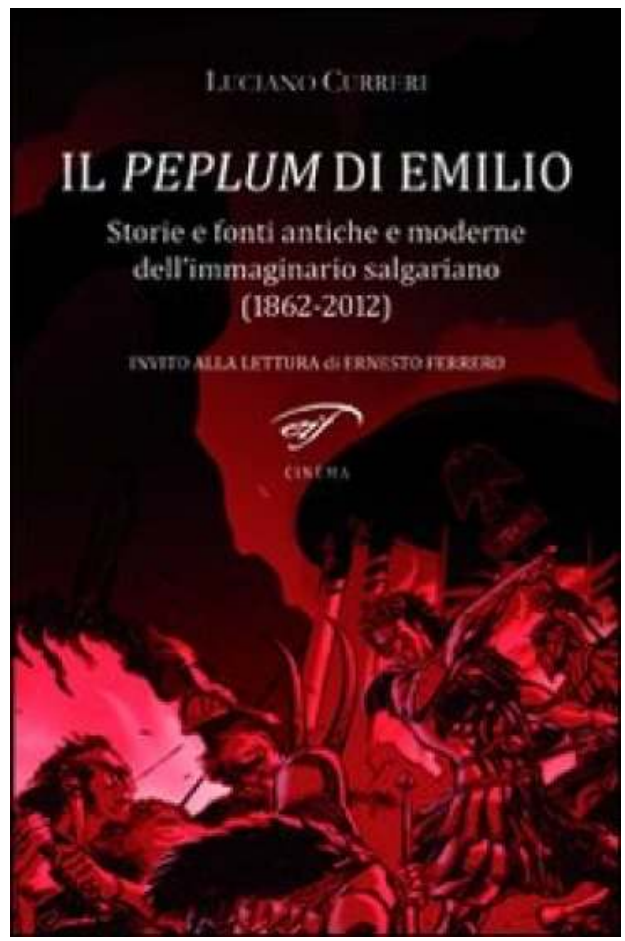

2 Un libro composito, una raccolta di articoli di variabile lunghezza ma sempre acuta intensità che si muove su di una molteplicità di livelli, che se pende verso la modernità e il cinema non manca di confrontarsi con la letteratura, il passato e le fonti, la Storia contemporanea (e successiva) al romanziere, fra Italia e Francia, aprendosi a diversi spunti di riflessione, a volte mescolando le carte a disposizione e invertendo l'ordine del tempo, sciacquando vecchie concrezioni improduttive e date per scontate, a volte creando vorticosi e immaginifici turbinii di riferimenti colti. Il tutto accompagnato da un profondo rispetto per l'unicità e irriducibilità dell'opera di Salgari, mai venduta, mai canzonata.

3 Certo è che l'impressione che si ha del volume si confà bene all'immagine del peplum come di un'ampia veste, che con i suoi lembi arriva a toccare diversi generi ed epoche, a partire da due romanzi che possono essere considerati un po' come delle 'chicche' dimenticate di Salgari. È proprio vero quel che dice Ernesto Ferrero nel suo invito alla lettura: "Salgari ci fa un ultimo regalo indiretto con le ricerche che lo riguardano, e che finiscono con l'andare oltre la sua lussureggiante produzione, investendo costumi culturali, gusti, tradizioni, passioni, manie, ossessioni, fantasticherie di un'intera epoca". Il peplum di Emilio è proprio questo: un libro che nella sua stessa struttura compositiva si insinua dentro Salgari riportandolo alla sua essenza, in un tempo mitico e fondativo - in cui "la sua auctoritas narrativa si scioglie dentro un immaginario puro, disteso tra antichità e modernità" - dove lo stesso romanziere rinasce salgariano: “ecco, alla fine della fiera, l'aggettivo, 'salgariano', conta più del cognome da cui è tratto e anzi ne sfuma il carattere monolitico, dandoci la possibilità di mettere insieme Flaubert e Salgari, Salgari e d'Annunzio e/o Pastrone".

4 Curreri si muove veloce sopra le righe offrendoci una cura contro quell'acribia "che può nascondere insidie, a partire dall'ossessione di voler tutto spiegare o sublimare", sussurrando fotogrammi e suggerendo contestualizzazioni in una scoppiettante danza del fuoco, dove il crepitio e l'allegrezza delle fiamme si alterna all'impeto e alla 
passione che divora in lungo e in largo. Nella sua "pirotecnia flamboyante" - se proprio si vuole dar 'fuoco alle micce' -, ci si può forse chiedere se non ci si ritrovi a volte a percepire proprio quella tensione che l'autore attribuisce a Salgari, in cui "ogni episodio, ogni informazione, ogni immagine possono e devono essere utilizzati, bruciati, consumati" (p. 168). Allora al fuoco, come già il nostro giustamente intuisce, va forse aggiunta dell'acqua, non tanto per 'spegnere', quanto per nutrire e permettere a chi ha già valicato le Alpi di acquisire quelle abilità natatorie che gli possono permettere di attraversare il fiume con Amytis.

\section{AUTORI}

\section{FABIANA DIMPFLMEIER}

Università di Roma 'La Sapienza' 